\title{
ABCA1 Gene Variation and Heart Disease Risk Reduction in the Elderly during Pravastatin Treatment
}

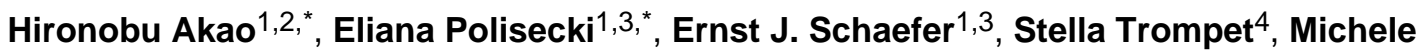 \\ Robertson $^{5}$, lan Ford ${ }^{5}$, J. Wouter Jukema ${ }^{4}$, Anton J. M. de Craen ${ }^{4}$, Christopher Packard ${ }^{6}$, \\ Brendan M. Buckley ${ }^{7}$, Kouji Kajinamion ${ }^{2}$, and on behalf of the PROspective Study of \\ Pravastatin in the Elderly at Risk (PROSPER) Investigator
}

\begin{abstract}
${ }^{1}$ Lipid Metabolism Laboratory, Jean Mayer USDA Human Nutrition Research Center on Aging at Tufts University and Tufts University School of Medicine, Boston, MA USA ${ }^{2}$ Department of Cardiology, Kanazawa Medical University, Uchinada, Japan ${ }^{3}$ Boston Heart Diagnostics, Framingham, MA ${ }^{4}$ Departments of Cardiology, Gerontology, and Geriatrics, Leiden University Medical Centre, Leiden, The Netherlands ${ }^{5}$ Robertson Centre of Biostatistics, University of Glasgow, Glasgow, Scotland, UK ${ }^{6}$ Department of Vascular Biochemistry, University of Glasgow, Glasgow, Scotland, UK ${ }^{7}$ Department of Pharmacology and Therapeutics, University College Cork, Cork, Ireland
\end{abstract}

\section{Abstract}

\begin{abstract}
Aims-Our goals were to examine the relationships of a specific ATP-binding cassette transporter A1 (ABCA1) variant, rs2230806 (R219K), on baseline lipids, low density lipoprotein (LDL) cholesterol lowering due to pravastatin, baseline heart disease, and cardiac endpoints on trial.
\end{abstract}

\begin{abstract}
Methods and Results-The $\boldsymbol{A B C A 1}$ R219K variant was assessed in 5,414 participants in PROSPER (PROspective Study of Pravastatin in the Elderly at Risk) (mean age 75.3 years), who had been randomized to pravastatin $40 \mathrm{mg} /$ day or placebo and followed for a mean of 3.2 years. Of these subjects $47.6 \%$ carried the variant, with $40.0 \%$ carryin $g$ one allele, and $7.6 \%$ carrying both alleles. No effects on baseline LDL cholesterol levels were noted, but mean HDL cholesterol increased modestly according to the number of variant alleles being present ( $1.27 \mathrm{vs} 1.28$ vs 1.30 $\mathrm{mmol} / \mathrm{L}, \mathrm{p}=0.024)$. No relationships between the presence or absence of this variant and statin induced LDL lowering response or CHD at baseline were noted. However within trial those with the variant as compared to those without the variant, the overall adjusted hazard ratio for new cardiovascular disease (fatal CHD, non-fatal myocardial infarction, or fatal or non-fatal stroke) was 1.22 (95\% CI 1.06-1.40, $\mathrm{p}=0.006)$, w hile for those in the pravastatin group it was 1.41
\end{abstract}

Correspondence to Kouji Kajinami, MD Department of Cardiology, Kanazawa Medical University, 1-1 Daigaku, Uchinada, Ishikawa 920-0293, Japan. kajinami@ kanazawa-med.ac.jp, Phone: +81-76-286-2211, Fax: +81-76-286-3780.

Drs. Akao and Polisecki contributed equally to this manuscript.

Publisher's Disclaimer: This is a PDF file of an unedited manuscript that has been accepted for publication. As a service to our customers we are providing this early version of the manuscript. The manuscript will undergo copyediting, typesetting, and review of the resulting proof before it is published in its final citable form. Please note that during the production process errors may be discovered which could affect the content, and all legal disclaimers that apply to the journal pertain. 
$(1.15-1.73, \mathrm{p}=0.001)$, and for those in the placebo group it was $1.08(0.89-1.30, \mathrm{p}=0.447)(\mathrm{p}$ for interaction 0.058).

Conclusion-Our data indicate that subjects with the $\boldsymbol{A B C A 1}$ R219K variant may get significantly less heart disease risk reduction from pravastatin treatment than those without the variant.

\section{Keywords}

ABCA1 Gene; Statins; Low Density Lipoprotein Cholesterol Lowering Response; Heart Disease Risk Reduction

\section{Introduction}

Elevated low-density lipoprotein cholesterol (LDL-C) and reduced high-density lipoprotein cholesterol (HDL-C) levels independently predict the risk of developing coronary heart disease (CHD) (1,2). Statins reduce LDL-C effectively, but considerable inter-individual variation exists in treatment responses. Previous pharmacogenetic studies have explored genetic variation as determinants of statin response. We have previously documented that genetic variation at the $\boldsymbol{A P O E}$, low density lipoprotein receptor $(\boldsymbol{L D L R})$, proprotein convertase subtilisin/kexin type 9 (PCSK9), the Niemann-Pick C1-like protein (NPC1L1), and the solute carrier organic anion transporter (SLCO1B1) and the kinesin like protein (KIF6) gene loci affects the degree of statin induced LDL-C lowering response in the PROspective Study of Pravastatin in the Elderly at Risk (PR O S PE R) (3-7). Moreover in this same study we have docu mented that genetic variation at the APOE, LDLR, NPC1L1, KIF6, and the taste receptor type 2, member 50 (TAS2R50) gene loci affected on trial CHD risk $(3,5,7)$.

In prosper, there was a significant interaction $(\mathrm{p}=0.0069)$ between baseline HDL-C levels and treatment effect. Subjects in the lowest HDL-C tertile (with baseline HDL-C $<1.11$ $\mathrm{mmol} / \mathrm{L}$ or $<43 \mathrm{mg} / \mathrm{dl}$ ) experienced apparently a greater benefit in terms of CHD risk reduction from pravastatin (hazards ratio 0.64 ) than did subjects with higher HDL-C levels (8). The ATP binding cassette transporter A1 (ABCAI) has been found to be critical in promoting the efflux of cellular cholesterol and phospholipid onto small pre-beta $1 \mathrm{HDL}$ particles and in the process converting them to larger alpha migrating HDL particles (9).

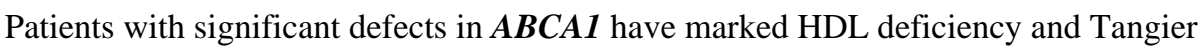
disease, characterized by cholesterol deposition in the tonsils, liver, spleen, and neurologic

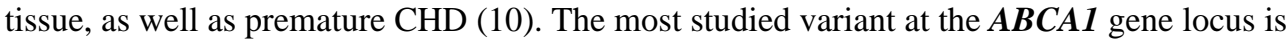
the $\mathrm{R} 219 \mathrm{~K}$ variant which causes an amino substitution in which an arginine is replaced by a

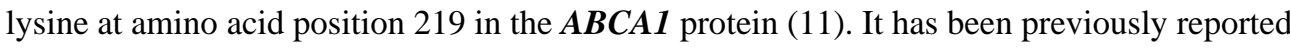
that individuals carrying the $\mathrm{R} 219 \mathrm{~K}$ variant (found in $46 \%$ of a population of 790 subjects) had significantly lower triglyceride levels, slightly higher HDL-C levels, and significantly reduced severity of CHD as compared to non-carriers (12). Moreover these authors

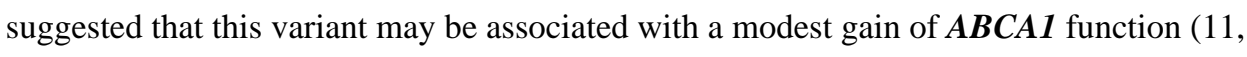
12). Subsequently it was reported that the presence of the $\mathrm{R} 219 \mathrm{~K} \boldsymbol{A B C A 1}$ variant in patients with familial hypercholesterolemia $(\mathrm{n}=374)$ was associated with a markedly reduced risk of CHD (hazards ratio 0.32, $\mathrm{p}<0.001$ ) as compared to non-carriers (13). A recent meta analysis 
based on an examination of 6,597 CHD cases and 15,369 controls concluded that the presence of the R219K $\boldsymbol{A B C A 1}$ variant was associated with a lower risk of CHD (hazards ratio $0.76, \mathrm{p}<0.0001$ ), and modestly higher HDL-C levels (14).

However, there are no studies to our knowledge that have assessed whether the R219K $A B C A 1$ genetic variant affects responses to statin treatment in terms of lipid modification or

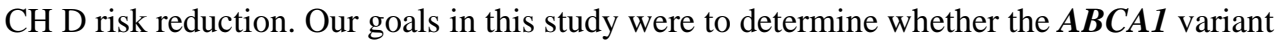
rs2230806 or R219K in PROSPER participants would affect baseline lipids, CHD prevalence at baseline, pravastatin induced LDL-C lowering, and pravastatin mediated CHD risk reduction.

\section{Materials and Methods}

\section{Study Subjects}

The results and the methodology used in the PROspective Study of Pravastatin in the Elderly at Risk (PROSPER) study have been previously described $(8,15)$. In this study 2,804 men and 3,000 women, aged 70-82 years, with pre-existing vascular disease $(n=2,404)$ or at least one of three major vascular risk factors (diabetes $n=575$, smoking $\mathrm{n}=1,433$, or hypertension $\mathrm{n}=3,360)$ were randomized to pravastatin $40 \mathrm{mg} /$ day $(\mathrm{n}=2,891)$ or placebo $(n=2,913)$ and followed for an average of 3.2 years. Over this time period, the mean LDL-C reduction in the active treatment group was $32 \%$, and the risk of developing CHD was decreased by $19 \%$, which was statistically significant (8).

\section{Biochemical and DNA analysis}

Total cholesterol (TC), HDL-C, and triglycerides were assessed after an overnight fast, at 6 months, and at 12 months, and LDL-C was calculated by the Friedewald formula, as previously described (8). Apolipoprotein A-I (apoA-I) and apolipoprotein B (apoB) were measured only at baseline as described. DNA was isolated from cells from this cohort and DNA from 5,783 subjects participating in this study were available for this study. ApoE phenotype was determined on plasma samples by Western blotting, using the method of Havekes et al. in the central laboratory of the Royal Infirmary in Glasgow, Scotland. Subjects were classified according to the presence of apoE2, apoE3, or apoE4 bands on gel blotting (16). This gel phenotyping method has been shown to have $99 \%$ concordance with genotyping (17).

For DNA analysis the single nucleotide polymorphism (SNP), R219K (rs2230806) of the $\boldsymbol{A B C A 1}$ gene was genotyped using Taq Man ${ }^{\circledR}$ SNPs genotyping assays (Applied Biosystems, Foster City, CA). The custom assay identification number was C_2741051_1. The end point was read after PCR amplification was performed using an Applied Biosystems 7900 HT Sequence Detection System. Genotypes with quality scores below the 95\% were repeated $(\mathbf{n = 1 3})$ and 5\% blinded replicates for genotype determinations were performed. In addition, a total of 119 subjects or $2.2 \%$ who had the apoE4/2 phenotype were excluded from these analyses, as well as 246 subjects who had missing apoE phenotypes. These exclusions were carried out because apoE phenotype or genotype can affect statininduced LDL-C lowering response, as well as CHD risk. Subjects carrying the apoE4 allele 
have the lowest statin-induced LDL-C lowering response and the highest CHD risk, while the converse is true for carriers of the apoE2 allele (18-21). The subject characteristics for these individuals representing the $\mathbf{5 , 4 1 4}$ subjects studied are shown in Table1.

\section{Statistical analysis}

Observed genotype frequencies were compared with those expected under Hardy-Weinberg equilibrium using a $\chi^{2}$ test. For data analysis, multivariate analysis of covariance (ANCOVA) was performed to detect associations between lipoprotein levels at baseline as well as changes in response to treatment with pravastatin at 6 months and with $\boldsymbol{A B C A I}$ genotypes adjusted for gender, body mass index, age, alcohol, smoking, diabetes, apoE phenotype, baseline HDL-C levels, and country of origin, since subjects participating in PR O S P E R were either from Scotland, Ireland, or the Netherlands. Prevalence at baseline of myocardial infarction (MI) and all types of vascular disease (history of angina, claudication, MI, stroke, transient ischemic attack, peripheral arterial disease surgery, or amputation for vascular disease more than 6 months before study entry) at baseline, as well as incidence of primary endpoints (CHD death or nonfatal MI or fatal non-fatal stroke), and all cardiovascular events (primary endpoints and coronary artery bypass grafting, coronary angioplasty, and peripheral artery surgery or angioplasty), were co mpared between carriers of different $\boldsymbol{A B C A 1}$ SNP genotypes using multivariable logistic regression analysis in all subjects, and also with stratification by gender and treatment. All analyses were fully adjusted for age, gender, country, history of vascular disease, body mass index, history of diabetes, as well as history of hypertension, alcohol use, current smoking, apoE phenotype, and baselin e HDL-C levels. We estimated the power of the study to detect genotypic differences in the incidence of cardiovascular events by assuming an alpha-level of 0.05 , a dominant inheritance model, an assumed prevalence of events of $15 \%$ and a power of $80 \%$ for a balanced case-control study (1:1) for minor allele frequency 0.30 , and genetic relative risk may around 1.2, which indicated approximately 2,000-2,500 as the number of cases per group required.

To evaluate the modifying effects of genotypes and gender on the response to treatment, gene-treatment and gene-gender interaction terms were added to the regression models. There was no interaction between R219K and apoE phenotype. All analyses were performed using SAS/STAT and SAS/Genetics (SAS Version 9.1, SAS Institute Inc., Cary, NC). A two-sided $\mathrm{p}<0.05$ was considered statistically significant. As for correction of multiple testing, we applied Bonferroni correction and the p-value threshold of 0.05 was divided by the number of independent tests.

\section{Results}

As summarized in Table 1, the participating subjects were elderly, with a median age of $75 \pm 3$ years at baseline. Mean LDL-C levels were in the moderate-risk category (3.36-4.14 $\mathbf{m m o l} / \mathbf{L}$ or $130-160 \mathrm{mg} / \mathbf{d l}$ ), as defined by the U nited States National Cholesterol Education Progra $m$ (22). Approxim ately half of the men and about one third of the women reported a history of any type of vascular disease. Data on apoE phenotype distribution in 
this population are also shown in Table 1. Genotype frequencies for the $\boldsymbol{A B C A 1}$ SNP examined conformed to Hardy-Weinberg equilibrium ( $p>0.05$, data not shown).

\section{Association with Baseline Lipid Levels}

Neither baseline LDL-C or triglyceride levels differed significantly among the three genotypic groups. However mean HDL-C levels increased modestly according to the number of variant allele present ( 1.27 versus 1.28 versus $1.30 \mathrm{mmol} / \mathrm{L}, \mathrm{p}=0.024)$ (Table 2). After gender separation, similar trend in terms of HDL-C levels was observed although statistical significance was no longer present (Table 2).

\section{Associations with Lipid Response to Treatment}

To determine whether the $\mathrm{R} 219 \mathrm{~K}$ variant affected lipid responses to pravastatin, the association between the R219K variant under study and 6 month and 12 month changes in TC, LDL-C, HDL-C, and triglyceride levels in individuals treated with pravastatin or placebo were examined. No significant relationships between the presence or absence of this variant and statin induced LDL-C response (Table 3 ) or changes in other lipid parameters including triglycerides or HDL-C levels (data not shown) were noted.

\section{Associations with History and within Trial Incidence of Cardiovascular Disease}

There were no significant associations between the prevalence of various forms of vascular disease at baseline and the presence of the $\mathrm{R} 219 \mathrm{~K}$ variant (data not shown). As shown in Tables 2, 3A and 3B, the number of AA homozygotes in placebo or pravastatin group was around 100, and cases with primary endpoint were 10 to 20 in each gender. Therefore, we examined variant effects in a dominant model, not additive model, to avoid false positive or negative association. In Table 4, we show the data on the relationships between $\boldsymbol{A B C A \boldsymbol { I }}$ genotypes and cardiovascular endpoints within trial. For all subjects, there was a significantly increased risk of new cardiovascular disease (fatal CHD, non-fatal myocardial infarction, or fatal or non-fatal stroke) on trial for those who carried the $\boldsymbol{A B C A 1} \mathrm{R} 219 \mathrm{~K}$ variant as compared to those who did not. The overall adjusted hazard ratio on trial for carriers versus non-carriers was $1.22(95 \% \mathrm{CI} 1.06-1.40, \mathrm{p}=0.006)$. Examining two treatment arms, it was seen that for carriers in the placebo group the HR was $1.08(0.89-1.30$, $\mathrm{p}=0.447)$, while for carriers in the pravastatin group it was $1.41(1.15-1.73, \mathrm{p}=0.001)$. An interaction between this genetic variation and treatment benefit was very close to statistical significance ( $\mathrm{p}=0.058$ ), suggesting that the $\mathrm{R} 219 \mathrm{~K}$ variant is a novel genetic marker for pravastatin treatment benefit in the elderly. Similar findings for this variant were observed in both men and women (Table 4), but an interaction between this genetic variant and treatment benefit (primary endpoint) in both gender did not reach statistical significance, $\mathrm{p}=0.206$ in men and 0.148 in women.

\section{Discussion}

We examined the association of a prevalent genetic polymorphis m, R219K, at the $\boldsymbol{A B C A I}$ gene locus with baseline lipids and vascular disease, pravastatin induced LDL-C lowering response, and cardiovascular endpoints on trial in PROSPER, in which participants who had been randomized to pravastatin $40 \mathrm{mg} /$ day or placebo and were followed for a mean of 3.2 
years (8). We found that the presence of this variant was associated with modestly, but significantly greater levels of baseline HDL-C. More importantly we noted that, in this trial of pravastatin in elderly subjects, those on active treatment carrying variant allele had a significantly greater cardiovascular risk (close to that in the placebo group) than those on pravastatin without the variant.

Amino acid 219 is located in the long extracellular loop of $\boldsymbol{A B C A 1}$, a region of the transporter known to contain various glycosylation sites $(23,24)$. The substitution of an arginine by a lysine at this residue probably alters the conformation of the extracellular domain of the $\boldsymbol{A B C A 1}$ protein, and enhances its interaction with apoAI, thereby increasing the efficiency of phospholipid and cholesterol transfer from the plasma membrane to HDL particles (25-27). These increases could therefore elevate baseline HDL-C levels. To date, the association between $\boldsymbol{A B C A 1} \mathrm{R} 219 \mathrm{~K}$ variant and increased HDL-C level remains controversial. To our knowledge, only one small study examined potential effects of the $\mathrm{R} 219 \mathrm{~K}$ variant on statin-induced lipid responses (28). These investigators reported similar LDL-C reductions among the three $\boldsymbol{A B C A 1}$ genotypic groups after 12 weeks of treatment with pravastatin. Our study in a much larger population with a longer treatment period supports these prior observations and indicates that this polymorphism does not play a significant role as a determinant of LDL-C lowering response to pravastatin treatment.

Our study did not provide direct evidence for the mechanism by which the R219K variant affect the statin effects in cardiovascular event reduction. Wild-type homozygotes for this variant showed significantly lower HDL-C levels at baseline. If this could be recognized as a simple representation of high-risk population, our observation might be the case that greater benefit from pravastatin treatment could be expected in the higher risk group. Another possible mechanism is that $\mathrm{R} 219 \mathrm{~K}$ variant plays a novel role in lipid metabolism. Supporting this is a recent study suggesting that the R219K variant not only affects apo A-I and HDL metabolism, but may also significant influence postprandial lipid metabolism (29). Further in vitro and in vivo study would clearly be required to establish the significance of this genetic variation as determinant for statin response. In comparison with previous studies, the present results are concordant with some and discordant with others to investigate $\boldsymbol{A B C A 1}$ polymorphism with respect to both cardiovascular diseases and statin response. As for $\mathrm{R} 219 \mathrm{~K}$ variant, a meta-analysis including 5,388 participants reported opposite genotype effects, $\mathrm{K}$-variant as a protective allele, in Chinese population (30). However, authors of this report found significantly more frequent prevalence of K-variant allele in Chinese population as compared to Caucasians, and recommended the interpretation with great caution. Another meta-analysis including 42 studies for R219K variant reported a potential protective role of $\mathrm{K}$-allele, but again suggested limited interpretation of results because of significant heterogeneity among enrolled studies (31). As

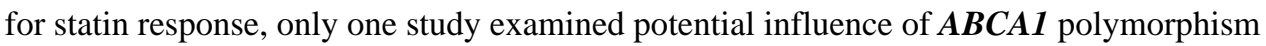
(32). This pharmacogenetic study enrolled 1,686 patients with familial hypercholesterolemia without history of coronary heart disease and analyzed statin- $\boldsymbol{A B C A 1 ~ C 6 9 T , ~ n o t ~ R 2 1 9 K , ~}$ polymorphism interaction by comparing treated and untreated patients. They found that TT genotype was associated with increased disease risk in untreated patients, but that the risk was no longer significantly different between genotypes, at least partially explained by a 
higher rise in HDL-C levels (despite similar pretreatment levels) during statin treatment in TT individuals. Effects of this polymorphism on $\boldsymbol{A B C A 1}$ transcription were proposed, but further studies appear to be required to confirm this consideration. In addition, difference in study populations, familial hypercholesterolemia without coronary disease (mean age 39 years) in this study and elderly (75 years) in our study could not allow us to consider these two studies equally.

In the original analysis in PROSPER, subgroup analysis demonstrated that the benefit of pravastatin in the prevention for primary endpoint was predominantly in the lowest tertile of HDL-C with significant interaction (8). Our current observations, associations with wild allele homozygosity, lower HDL-C levels, and fewer cardiovascular events on pravastatin, could provide one possible genetic explanation for this finding. This kind of issue which could only be obtained through a well-conducted large randomized study enrolling significant number of both genders and examining genotypic effects on treatment response is the most important strength of the present study. Despite that the primary weakness of the study is its narrow focus, only one polymorphism investigated and lack of providing evidence of possible explanation for observations, further in vitro and clinical studies are required to extend our observations to more wide range of populations.

In conclusion, $\boldsymbol{A B C A 1} \mathrm{R} 219 \mathrm{~K}$ variant might be a novel genetic determinant for pravastatin treatment response in heart disease risk reduction in the elderly.

\section{Acknowledgments}

We would like to express our sincere appreciation to Dr. James Shepherd, the principal investigator of original PROSPER Study. We also thank all members of the PROSPER research team.

Funding This research was supported by grant R01 HL74753 from the National Institutes of Health (EJS), contract 53-1950-5-003 fro m the Agricultural Research Service of the US Department of Agriculture (EJS), by the Rotary Foundation, Evanston, Illinois (HA), and by Grant for Specially Promoted Research from Kanazawa Medical University (SR2012-02) (HA), by a Grant for C ollaborative Research fro m Kanazawa Medical University (C2011-3) (KK), and by Grants for Project Research from the High-Tech Research Center of Kanazawa Medical University (2010-2012, 2011-2012) (KK). Support for this research provided by the seventh framework program of the European commission (grant 223004) and by the Netherlands Genomics Initiative (Netherlands Consortium for Healthy Aging grant 050-060-810) (JWJ).

Research Support: This research was supported by grant R01 HL74753 from the National Institutes of Health (EJS), and contract 53-1950-5-003 from the Agricultural Research Service of the US Department of Agriculture (EJS). Dr. Akao was supported by a Scholarship from the Rotary International, and by Grant for Specially Promoted Research from Kanazawa Medical University (SR2012-02).

Dr. Kajinami was supported by a Grant for Collaborative Research from Kanazawa Medical University (C2011-3), and by Grants for Project Research from the High-Tech Research Center of Kanazawa Medical University (2010-2012, 2011-2012).

Support for this research was provided by the seventh framework program of the European commission (grant 223004) and by the Netherlands Genomics Initiative (Netherlands Consortium for Healthy Aging grant 050-060-810).

\section{References}

1. Ingelsson E, Schaefer EJ, Contois JH, McNamara JR, Sullivan L, Keyes MJ, Pencina MJ, Schoonmaker C, Wilson PW, D'Agostino RB, Vasan RS. Clinical utility of different lipid measures for prediction of coronary heart disease in men and women. JAMA. 2007; 298:776-85. [PubMed: 17699011] 
2. Wilson PW, D'Agostino RB, Levy D, Belanger AM, Silbershatz H, Kannel WB. Prediction of coronary heart disease using risk factor categories. Circulation. 1998; 97:1837-47. [PubMed: 9603539]

3. Polisecki E, Muallem H, Maeda N, Peter I, Robertson M, Mc Mahon AD, Ford I, Packard C, Shepherd J, Jukema JW, Westendorp RG, de Craen AJ, Buckley BM, Ordovas JM, Schaefer EJ. Prospective Study of Pravastatin in the Elderly at Risk (PROSPER) Investigators Genetic variation at the LDL receptor and HMG-CoA reductase gene loci, lipid levels, statin response, and cardiovascular disease incidence in PROSPER. Atherosclerosis. 2008; 200:109-14. [PubMed: 18261733]

4. Polisecki E, Peter I, Robertson M, McMahon AD, Ford I, Packard C, Shepherd J, Juke ma JW, Blauw GJ, Westendorp RG, de Craen AJ, Trompet S, Buckley BM, Murphy MB, Ordovas JM, Schaefer EJ. PROSPER Study Group Genetic variation at the PCSK9 locus moderately lowers lowdensity lipoprotein cholesterol levels but does not significantly lower vascular disease risk in an elderly population. Atherosclerosis. 2008; 200:95-101. [PubMed: 18262190]

5. Polisecki E, Peter I, Simon JS, Hegele RA, Robertson M, Ford I, Shepherd J, Packard C, Jukema JW, de Craen AJ, Westendorp RG, Buckley BM, Schaefer EJ. Prospective Study of Pravastatin in the Elderly at Risk (PROSPER) Investigators Genetic variation at the NPC1L1 gene locus, plasma lipoproteins, and heart disease risk in the elderly. J Lipid Res. 2010; 51:1201-07. [PubMed: 19752398]

6. Akao H, Polisecki E, Kajinami K, Trompet S, Robertson M, Ford I, Jukema JW, de Craen AJ, Westendorp RG, Shepherd J, Packard C, Buckley BM, Schaefer EJ. Genetic variation at the SLCO1B1 gene and low density lipoprotein cholesterol lowering response to pravastatin in the elderly. Atherosclerosis. 2012; 220:413-417. [PubMed: 22189199]

7. Akao H, Polisecki E, Kajinami K, Trompet S, Robertson M, Ford I, Jukema JW, de Craen AJ, Westendorp RG, Shepherd J, Packard C, Buckley BM, Schaefer EJ. KIF6, LPA, TAS2R50, and VAMP8 genetic variation, low density lipoprotein cholesterol lowering response to pravastatin, and heart disease risk reduction in the elderly. Atherosclerosis. 2012; 220:456-462. [PubMed: 22192511]

8. Shepherd J, Blauw GJ, Murphy MB, Bollen EL, Buckley BM, Cobbe SM, Ford I, Gaw A, Hyland M, Jukema JW, Kamper AM, Macfarlane PW, Meinders AE, Norrie J, Packard CJ, Perry IJ, Stott DJ, Sweeney BJ, Twomey C, Westendorp RG. PROSPER study group PROspective Study of Pravastatin in the Elderly at Risk PROspective Study of Pravastatin in the Elderly at Risk Pravastatin in elderly individuals at risk of vascular disease (PROSPER): a randomised controlled trial. Lancet. 2002; 360:1623-30. [PubMed: 12457784]

9. Asztalos, BF.; Brunzell, J. The kinetics and remodeling of HDL particles: lessons from inborn errors of lipid metabolism. In: Schaefer, EJ., editor. High density Lipoproteins, dyslipidemia, and coronary heart disease. New York: Springer Publishing; p. 2010p. 33-44.

10. Schaefer EJ, Santos RD, Asztalos BF. Marked HDL deficiency and premature coronary heart disease. Current Opinion in Lipidology. 2010; 21:289-297. [PubMed: 20616715]

11. Frikke-Schmidt R. Genetic variation in the ABCA1 gene, HDL cholesterol, and risk of ischemic heart disease in the general population. Atherosclerosis. 2010; 208:305-316. [PubMed: 19596329]

12. Clee SM, Zwinderman AH, Engert JC, Zwarts KY, Molhuizen HO, Roomp K, Jukema JW, van Wijland M, van Dam M, Hudson TJ, Brooks-Wilson A, Genest J Jr, Kastelein JJ, Hayden MR. Common genetic variation in ABCA1 is associated with altered lipoprotein levels and a modified risk for coronary artery disease. Circulation. 2001; 103:1198-1205. [PubMed: 11238261]

13. Cenarro A, Artieda M, Castillo S, Mozas P, Reyes G, Tejedor D, Alonso R, Mata P, Pocoví M, Civeira F. Spanish FH group. A common variant in the ABCA1 gene is associated with a lower risk for premature coronary heart disease in familial hypercholesterolemia. J Med Genet. 2003; 40:163-168. [PubMed: 12624133]

14. Ma XY, Liu JP, Song ZY. Associations of the ATP-binding cassette transporter A1 R219K polymorphism with HDL-C level and coronary artery disease risk: a meta-analysis. Atherosclerosis. 2011; 215:428-434. [PubMed: 21310416]

15. Shepherd J, Blauw GJ, Murphy MB, Cobbe SM, Bollen EL, Buckley BM, Ford I, Jukema JW, Hyland M, Gaw A, Lagaay AM, Perry IJ, Macfarlane PW, Meinders AE, Sweeney BJ, Packard CJ, Westendorp RG, Twomey C, Stott DJ. The design of a prospective study of Pravastatin in the 
Elderly at Risk (PROSPER). PROSPER Study Group PROspective Study of Pravastatin in the Elderly at Risk. Am J Cardiol. 1999; 84:1192-97. [PubMed: 10569329]

16. Havekes LM, de Knijff P, Beisiegel U, Havinga J, Smit M, Klasen E. A rapid micromethod for apolipoprotein E phenotyping directly in serum. J Lipid Res. 1987; 28:455-63. [PubMed: 3585179]

17. Lahoz C, Osgood D, Wilson PW, Schaefer EJ, Ordovas JM. Frequency of phenotype-genotype discrepancies at the apolipoprotein E locus in a large population study. Clin Chem. 1996; 42:1817-23. [PubMed: 8906082]

18. Ordovas JM, Lopez-Miranda J, Perez-Jimenez F, Rodriguez C, Park JS, Cole T, Schaefer EJ. Effect of apolipoprotein E and A-IV phenotypes on the low density lipoprotein response to HMG CoA reductase inhibitor therapy. Atherosclerosis. 1995; 113:157-66. [PubMed: 7605354]

19. Pedro-Botet J, Schaefer EJ, Bakker-Arkema RG, Black DM, Stein EM, Corella D, Ordovas JM. Apolipoprotein E genotype affects plasma lipid response to atorvastatin in a gender specific manner. Atherosclerosis. 2001; 158:183-93. [PubMed: 11500190]

20. Wilson PW, Schaefer EJ, Larson MG, Ordovas JM. Apolipoprotein E alleles and risk of coronary disease: a meta-analysis. Arterioscler Thromb Vasc Biol. 1996; 16:1250-55. [PubMed: 8857921]

21. Lahoz C, Schaefer EJ, Cupples LA, Wilson PW, Levy D, Osgood D, Parpos S, Pedro-Botet J, Daly JA, Ordovas JM. Apolipoprotein E genotype and cardiovascular disease in the Framingham Heart Study. Atherosclerosis. 2001; 154:529-37. [PubMed: 11257253]

22. Expert Panel. Executive Summary of The Third Report of The National Cholesterol Education Program (NCEP) Expert Panel on Detection, Evaluation, And Treatment of High Blood Cholesterol In Adults (Adult Treatment Panel III). JAMA. 2001; 285:2486-97. [PubMed: 11368702]

23. Rust S, Rosier M, Funke H, Real J, Amoura Z, Piette JC, Deleuze JF, Brewer HB, Duverger N, Denèfle $\mathrm{P}$, Assmann $\mathrm{G}$. Tangier disease is caused by mutations in the gene encoding ATP-binding cassette transporter 1. Nat Genet. 1999; 22:352-5. [PubMed: 10431238]

24. Huang W, Moriyama K, Koga T, Hua H, Ageta M, Kawabata S, Mawatari K, Imamura T, Eto T, Kawamura M, Teramoto T, Sasaki J. Novel mutations in ABCA1 gene in Japanese patients with Tangier disease and familial high density lipoprotein deficiency with coronary heart disease Biochem Biophys. Acta. 2001; 1537:71-8.

25. Benton JL, Ding J, Tsai MY, Shea S, Rotter JI, Burke GL, Post W. Associations between two common polymorphisms in the ABCA1 gene and subclinical atherosclerosis: Multi-Ethnics Study of Atherosclerosis (MESA). Atherosclerosis. 2007; 193:352-60. [PubMed: 16879828]

26. Tall AR, Costet P, Wang N. Regulation and mechanisms of macrophage cholesterol efflux. J Clin Invest. 2002; 110:899-904. [PubMed: 12370265]

27. Villard EF, EI Khoury P, Frisdal E, Bruckert E, Clement K, Bonnefont-Rousselot D, Bittar R, Le Goff W, Guerin M. Genetic determination of plasma cholesterol efflux capacity is gender-specific and independent of HDL-cholesterol levels. Arterioscler Thromb Vasc Biol. 2013; 33:822-8. [PubMed: 23372063]

28. Li J, Wang LF, Li ZQ, Pan W. Effect of R219K polymorphos $m$ of the ABC A1 gene on the lipidlowering effect of pravastatin in chinese patients with coronary heart disease. Clin Exp Pharmacol Physiol. 2009; 39:567-570. [PubMed: 19673941]

29. Delgado-Lista J, Perez-Martinez P, Perez-Jimenez F, Garcia-Rios A, Fuentes F, Marin C, GómezLuna P, Camargo A, Parnell LD, Ordovas JM, Lopez-Miranda J. ABCA1 gene variants regulate postprandial lipid metabolism in healthy men. Arterioscler Thromb Vasc Biol. 2010; 30:10511057. [PubMed: 20185793]

30. Li YY, Zhang H, Qin XY, Lu XZ, Ynag B, Chen ML. ATP-binding cassette transporter A1 R219K polymorphism and coronary artery disease in Chinese population: a meta-analysis of 5,388 participants. Mil Biol Rep. 2012; 39:11031-11039.

31. Yin YW, Li JC, Gao D, Chen YX, Li BH, Wang JZ, Liu Y, Liao AQ, Zhang MJ, Gao CY, Zhang LL. Influence of ATP-biding cassette transporter $1 \mathrm{R} 219 \mathrm{~K}$ and M883I polymorphisms on development of atherosclerosis: a meta-analysis of 58 studies. PLoS One. 2014; 9:e86480. [PubMed: 24466114] 
32. Vermissen J, Oosterveer DM, Yazdanpanah M, Mulder M, Dehghan A, Defesche JC, Kastelein JJP, Sijbrands EJG. A frequent variant in the ABCA1 gene is associate with increased coronary heart disease risk and a better response to statin treatment in familial hypercholesterolemia. Eur Heart J. 2011; 32:469-475. [PubMed: 20595220] 


\section{Highlights}

The relationships of the $A B C A l$ variant (R219K), with baseline lipids, LDL lowering to pravastatin, baseline heart disease, and cardiac endpoints on PROSPER trial were examined.

Baseline HDL cholesterol associated with the variant, but LDL cholesterol did not.

The variant did not associate with LDL lowering response or CHD at baseline.

The adjusted hazard ratio for new CHD events of the variant in the pravastatin group was $1.41(\mathrm{p}=0.001)$, while that in the placebo group was $1.08(\mathrm{p}=0.447)$.

The $A B C A 1 \mathrm{R} 219 \mathrm{~K}$ variant may get significantly less heart disease risk reduction from pravastatin treatment. 


\section{Table 1}

\section{Study Subjects $(\mathbf{n}=5,414)$}

\begin{tabular}{|c|c|c|}
\hline Study Characteristics Mean (SD) ${ }^{a}$ & Placebo $(n=2,732)$ & Pravastatin $(n=2,682)$ \\
\hline Age (years) & $75.3(3.3)$ & $75.4(3.3)$ \\
\hline BMI $\left(\mathrm{kg} / \mathrm{m}^{2}\right)$ & $26.9(4.3)$ & $26.8(4.1)$ \\
\hline Females, n (\%) & $1413(51.7)$ & $1382(51.5)$ \\
\hline History diabetes mellitus, n (\%) & $294(10.8)$ & $281(10.5)$ \\
\hline History hypertension, n (\%) & $1694(62.0)$ & $1664(62.0)$ \\
\hline History vascular disease, n (\%) & 1191 (43.6) & $1211(45.2)$ \\
\hline History of MI, n (\%) & $374(13.7)$ & $356(13.3)$ \\
\hline Current smoking, n (\%) & $740(27.1)$ & 693 (25.8) \\
\hline Alcohol consumption (units per week) & $5.0(8.6)$ & $5.3(9.5)$ \\
\hline Total cholesterol (mmol/L) & $5.67(0.88)$ & $5.70(0.93)$ \\
\hline LDL-cholesterol (mmol/L) & $3.79(0.78)$ & $3.81(0.81)$ \\
\hline HDL-cholesterol (mmol/L) & $1.27(0.34)$ & $1.28(0.35)$ \\
\hline Triglyceride (mmol/L) & $1.53(0.69)$ & $1.55(0.71)$ \\
\hline apoA-I (g/L) & $1.32(0.24)$ & $1.33(0.25)$ \\
\hline $\operatorname{apoB}(g / L)$ & $1.15(0.22)$ & $1.15(0.23)$ \\
\hline apoE $2 / 2+2 / 3(\%)$ & 12.1 & 12.1 \\
\hline apoE 3/3 (\%) & 64.7 & 64.3 \\
\hline apoE 3/4+4/4 (\%) & 23.2 & 23.6 \\
\hline$A B C A 1$ 1_R219K-rs2230806 & MAF A:0.28 & \\
\hline
\end{tabular}

BMI: body mass index. MAF: minor allele frequency. MI: myocardial infarction

${ }^{a}$ Means (S.D.) unless otherwise specified; apoE 2/4 carriers were excluded (see Materials and Methods section) 
Table 2

Adjusted Baseline Lipid Levels (mean \pm SD) by Gender and Genotype

\begin{tabular}{lcccc}
\hline \multirow{2}{*}{$\boldsymbol{A B C A 1} \mathbf{~ S N P}$} & \multicolumn{3}{c}{$\mathbf{R 2 1 9 K}$} & $p^{\boldsymbol{a}}$ \\
\cline { 2 - 4 } rs2230806 & GG & GA & AA & \\
\hline All (n) & 2834 & 2167 & 413 \\
TC (mmol/L) & $5.69 \pm 0.91$ & $5.68 \pm 0.89$ & $5.75 \pm 0.93$ & 0.463 \\
LDL-C (mmol/L) & $3.81 \pm 0.80$ & $3.79 \pm 0.80$ & $3.80 \pm 0.80$ & 0.655 \\
HDL-C (mmol/L) & $1.27 \pm 0.34$ & $1.28 \pm 0.35$ & $1.30 \pm 0.34$ & 0.024 \\
TG (mmol/L) & $1.56 \pm 0.72$ & $1.53 \pm 0.69$ & $1.52 \pm 0.64$ & 0.140 \\
apoA-I (g/L) & $1.32 \pm 0.24$ & $1.33 \pm 0.25$ & $1.35 \pm 0.23$ & 0.066 \\
apoB (g/L) & $1.15 \pm 0.23$ & $1.15 \pm 0.23$ & $1.15 \pm 0.22$ & 0.222 \\
Men (n) & 1395 & 1040 & 184 & \\
TC (mmol/L) & $5.36 \pm 0.80$ & $5.36 \pm 0.80$ & $5.31 \pm 0.71$ & 0.819 \\
LDL-C (mmol/L) & $3.59 \pm 0.72$ & $3.58 \pm 0.73$ & $3.54 \pm 0.62$ & 0.820 \\
HDL-C (mmol/L) & $1.17 \pm 0.31$ & $1.18 \pm 0.33$ & $1.21 \pm 0.30$ & 0.133 \\
TG (mmol/L) & $1.50 \pm 0.74$ & $1.50 \pm 0.74$ & $1.44 \pm 0.59$ & 0.568 \\
apoA-I (g/L) & $1.24 \pm 0.21$ & $1.25 \pm 0.24$ & $1.26 \pm 0.22$ & 0.166 \\
apoB (g/L) & $1.11 \pm 0.22$ & $1.10 \pm 0.21$ & $1.09 \pm 0.19$ & 0.227 \\
Women (n) & 1439 & 1127 & 229 & \\
TC (mmol/L) & $6.00 \pm 0.89$ & $5.97 \pm 0.88$ & $6.11 \pm 0.93$ & 0.110 \\
LDL-C (mmol/L) & $4.01 \pm 0.81$ & $3.99 \pm 0.81$ & $4.07 \pm 0.82$ & 0.281 \\
HDL-C (mmol/L) & $1.36 \pm 0.35$ & $1.38 \pm 0.35$ & $1.40 \pm 0.34$ & 0.091 \\
TG (mmol/L) & $1.61 \pm 0.69$ & $1.55 \pm 0.64$ & $1.60 \pm 0.68$ & 0.127 \\
apoA-I (g/L) & $1.39 \pm 0.25$ & $1.40 \pm 0.24$ & $1.42 \pm 0.21$ & 0.221 \\
apoB (g/L) & $1.20 \pm 0.23$ & $1.18 \pm 0.22$ & $1.20 \pm 0.23$ & 0.577 \\
\hline & & & & \\
\hline
\end{tabular}

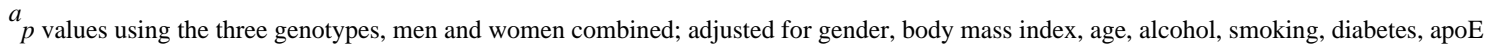
phenotype, and country. As for Bonferroni correction of multiple testing, p-value threshold divided by independent tests would be $0.05 / 12=0.004$. 

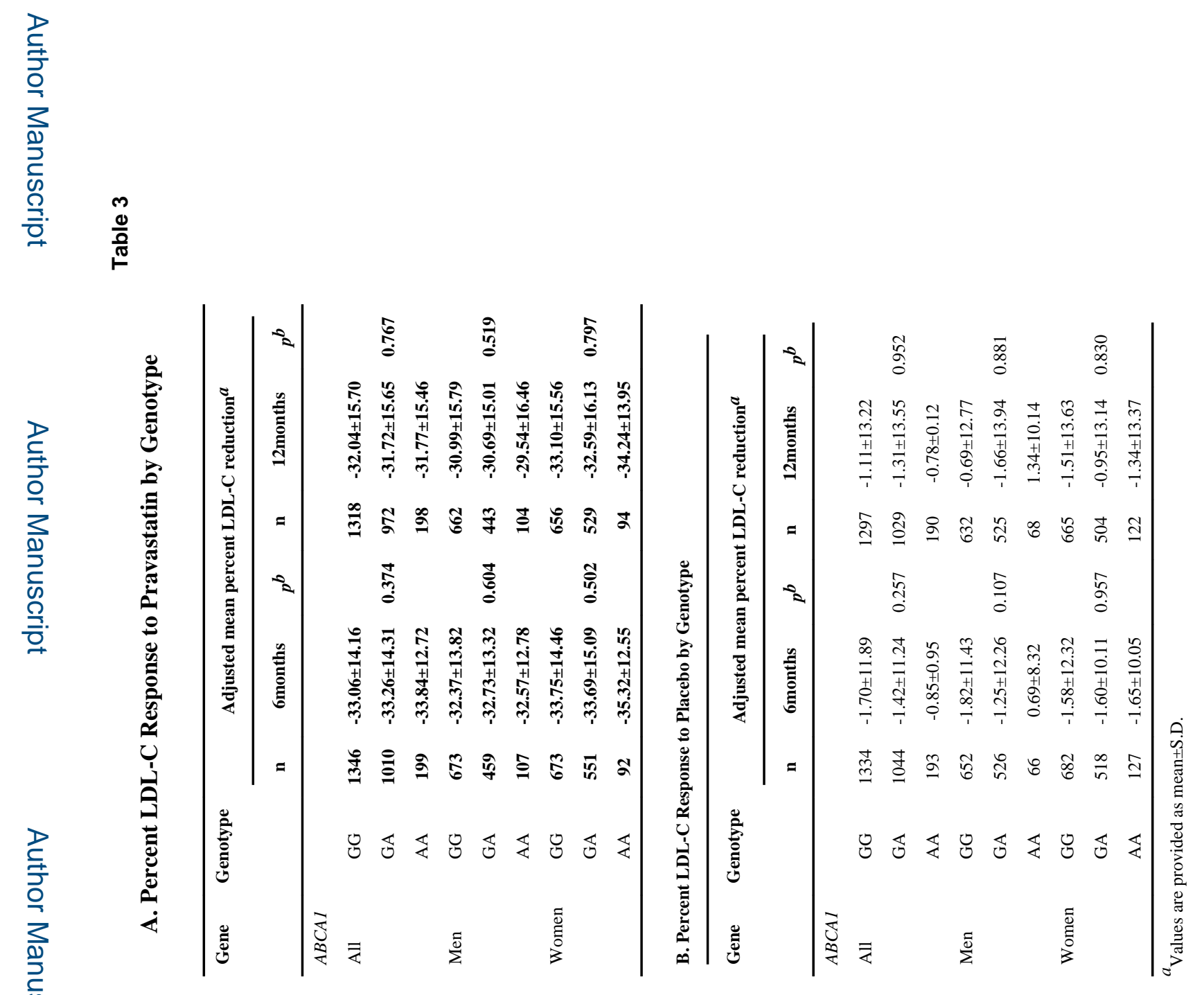


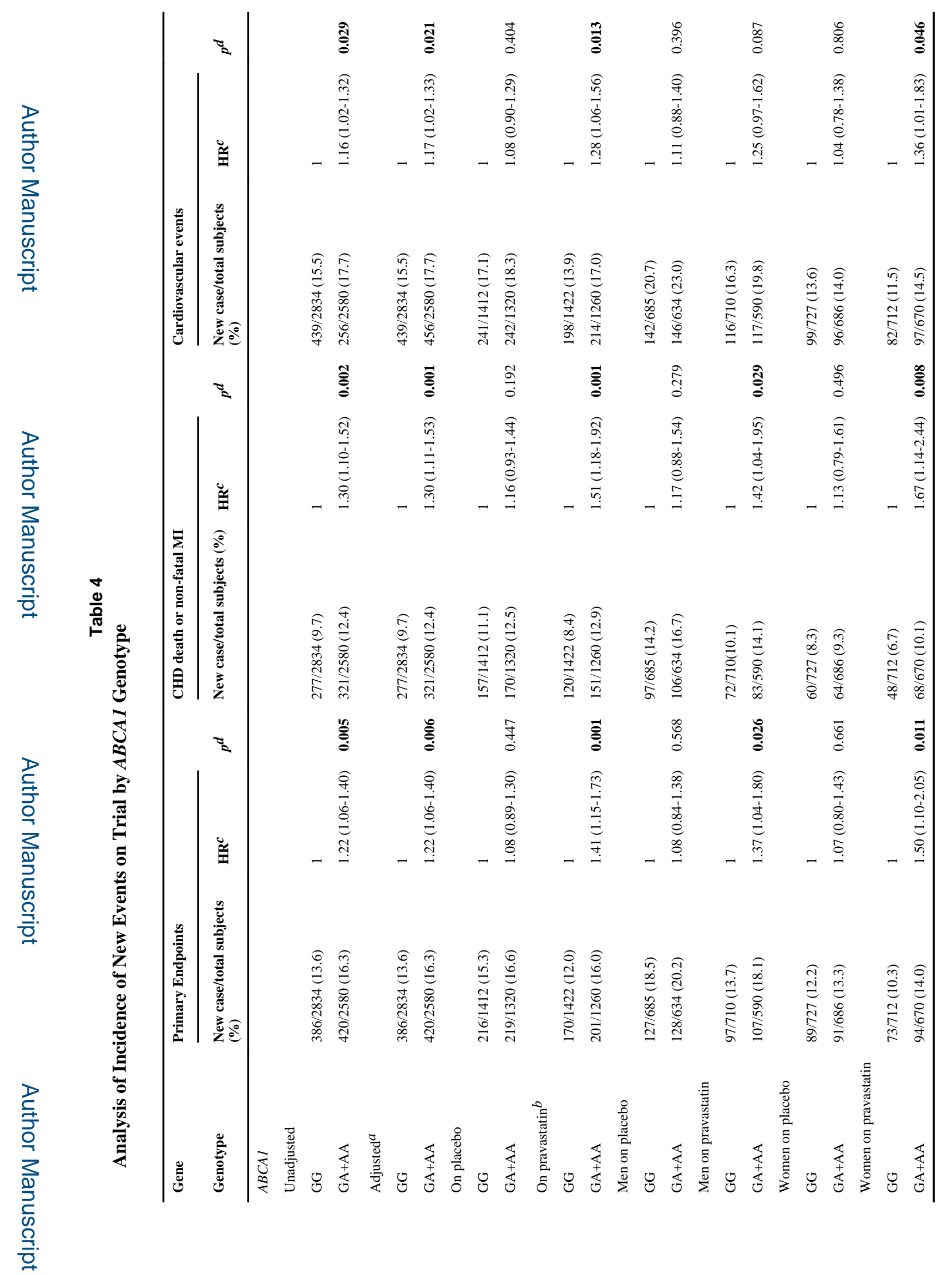

Atherosclerosis. Author manuscript; available in PMC 2015 September 01. 


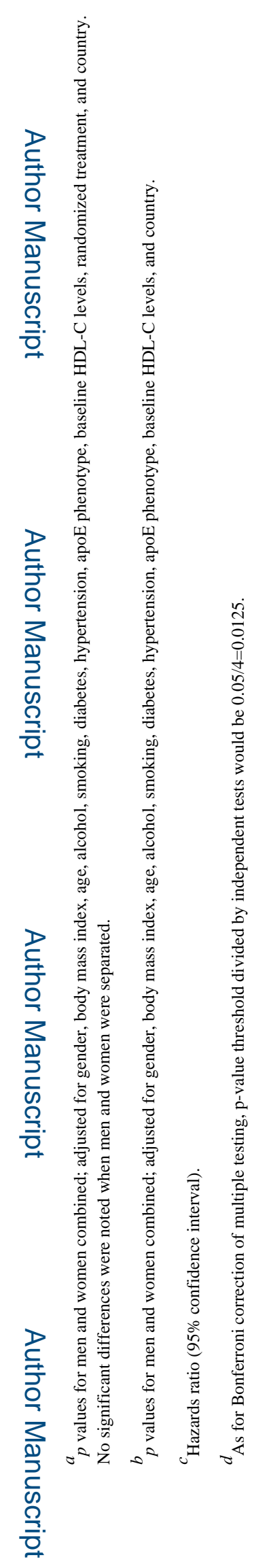

Atherosclerosis. Author manuscript; available in PMC 2015 September 01. 